\title{
Breve Reseña \\ de la Investigación Socio-jurídica del Programa de Derecho
}

\author{
Por: JOSÉ EDUARDO BERNAL BARRERA \\ Egresado del Programa de Derecho - Ex Decano y Ex Secretario General de la \\ Corporación Universitaria del Meta
}

En el mes de enero del año 2004, recibí con beneplácito una enorme responsabilidad de manos del doctor Rafael Mojica García, había sido nombrado Decano de la Escuela de Derecho y Ciencias Sociales, en ese nombramiento se me encargaba de manera muy especial el procesos de investigación, sin embargo surgieron inicialmente otras prioridades como fue el afrontar la reorganización de la escuela, que para ese momento contaba con dos programas, Derecho y Comunicación Social y que de paso sea dicho, se acababan de entregar los documentos en extenso - hoy maestros - de los estándares de calidad - hoy, de condiciones- para el trámite del registro calificado de los dos programas.

En el mes de julio de 2005, se retomó el tema de investigación al darse cuenta la institución de la exigencia que hacía el Decreto 1212 de 1991, a los programas de derecho de tener un centro de investigaciones sociojurídicas, fue así como de tarea se propuso conseguir un profesional de derecho que rigiera ese centro. El ojo clínico del señor Rector trajo al doctor Santiago Gómez Parra, quien en esos días se le había reconocido el estatus de pensionado. A partir de ese momento se inició la consolidación del Centro de Investigaciones Sociojurídicas Jorge Eliecer Gaitán.

Al mes de haberse creado ese centro, se contaba con dos abogados contratados de medio tiempo como investigadores, es decir el centro contaba ya, como Director del Centro, el doctor Gómez Parra y como investigadores auxiliares los doctores Edgar Isidro Baracaldo y Víctor Puerto, estos dos últimos profesionales se dedicaron a impulsar la creación de los primeros semilleros de investigación, que llegaron a tener hasta un aula contigua al centro de investigaciones de aquél entonces, en el segundo piso de la sede Carlina. A los semilleros creados, se auto propusieron como líderes para algunos de estos las doctoras Adriana Linares y Andrea Sierra.
El doctor Santiago Gómez en el mes de marzo de 2006 me informó que la Asociación Colombiana de Universidades - ASCUN- había abierto un concurso auspiciado por el periódico El Espectador, la Embajada de Francia y Editores Nuevo Mundo, proponiendo que se enviara una investigación adelantada por el semillero Marbechare compuesto por los estudiantes; Natalia Franco, Carlos Quevedo R. Faride Torres, Sandra Álvarez, Nasly Castro, Pablo Emilio Roa, Luis Fernando Fierro, Javier Moyano y Adriana Coca Carvajal de cuarto semestre nocturno de derecho. Teniendo en cuenta que el tema del concurso se relacionaba con los cultivos ilícitos en Colombia, el doctor Gómez Parra me manifestó que la investigación precisamente abordaba dicha problemática. El trabajo se titulaba: Cultivos Ilícitos en la Macarena "Eje Duda Guayabero". Le dije al Director del Centro de Investigaciones que la revisáramos y que la enviáramos, previo consentimiento del doctor Mojica. Así se hizo y el señor Rector asintió que se enviara el trabajo de investigación al concurso.

El lunes 4 de septiembre sobre las 6:10 am, me encontraba dictando la clase de derecho de la seguridad social, golpearon en la puerta, la cual abrí personalmente encontrándome con una persona que sostenía en sus manos una grabadora, me preguntó: ¿Es usted el doctor Bernal Decano de Derecho? Le respondí afirmativamente. Inmediatamente me propuso que si podía hacerme una entrevista en directo para el noticiero del Llano por el teléfono celular; le pregunté cuál era el motivo; me respondió, es para tener la chiva a nivel regional; luego usted no sabe que anoche en Bogotá le otorgaron un premio a la UNIMETA, por una investigación que presentaron a un concurso que fue impulsado por ASCUN? Le respondí medio atónito que era cierto que la facultad de derecho había presentado un trabajo de investigación de un semillero, pero que ignoraba que hubiéramos ganado el concurso. 
Le hice una referencia rápida del contenido de la investigación, de los estudiantes que hacían parte del semillero de investigaciones, comprometiéndome que en la emisión del medio día estaría con ellos en la emisora. A partir de ese momento la felicidad me embargó, mis estudiantes de sexto semestre a quienes les estaba dictando la clase expresaron su complacencia. Tan pronto salí de clase me encontré con el doctor Gómez Parra a quien le comenté lo sucedido, pude observar en su rostro un gran gesto de satisfacción. De inmediato le sugerí que telefónicamente le informáramos al señor Rector. Una vez se lo hicimos saber nos citó a la Rectoría. Ese día, ni los miembros del semillero, ni el señor Rector, ni el doctor Santiago, ni yo, dábamos abasto para atender las entrevistas en las distintas emisoras de Villavicencio.

El miércoles 6 de septiembre, viajamos a Bogotá a recibir el Premio Nacional al Mejor Trabajo en Investigación en Ciencias Sociales VI Versión y fue mayor la sorpresa para la Corporación Universitaria del Meta, cuando se supo que el grupo que compitió por ese primer puesto, había sido un grupo de investigaciones de postgrados de la Universidad Nacional de Colombia. Algunos de los jurados fueron los doctores: Gonzalo Andrade Correa, Julio Carrizosa, Carlos Gaviria Díaz, Orlando Fals Borda, Guillermo Páramo R. y Orlando Rangel, entre otros. ¡Querer es poder!

Entre el año 2005 y septiembre del 2008, el Centro de Investigaciones Socio-jurídicas Jorge Eliecer Gaitán, adelantó y publicó las siguientes cinco investigaciones: El Conflicto Armado en Colombia y la Ley de Alternatividad Penal o de Justicia y Paz

Investigador Principal: Santiago Gómez Parra

Cultivos Ilícitos en la Macarena "Eje Duda Guayabero" Investigador Principal: Adriana Milena Linares Rios Investigadores Auxiliares: Semillero Marbechare: Natalia Franco, Carlos Quevedo R. Faride Torres, Sandra Álvarez, Nasly Castro, Pablo Emilio Roa, Luis Fernando Fierro, Javier Moyano y Adriana Coca Carvajal

Eficacia de la Ayuda a los Desplazados Investigador Principal: Santiago Gómez Parra Investigadores Auxiliares: Andrea Bello, Solanyi Ortiz, Viviana Agudelo, Damarís Oñate, Laura Mesa y Tatiana Sabogal.

ElDesplazamientoForzadoCinturonesdeMiseria,Hábita t y Calidad de Vida - Caso Villavicencio.

Investigador Principal: Santiago Gómez Parra

Investigadores Auxiliares: Milena Villar, Mónica Llanés, Felipe Soto, Yair Ávila, Sonia Garzón, Rigoberto Figueredo, María Eugenia Ayala Grass, Marina Ayala Grass, Adriana Bocanegra, Gerardo Camacho, Julián Vivero y Gonzalo Zuluaga.

El Desplazamiento Forzado en Colombia - Caso Departamento del Meta.

Investigador Principal: Santiago Gómez Parra

Investigadores Auxiliares: Andrés Rodríguez, Marcela Chequemarca, Francisco Patiño, Hugo Sandoval, Paola Flórez, Jorge Beltrán, Javier Sejin e Isabel Otálora.

Se puede decir que esta ha sido la mejor época hasta la fecha de la investigación socio-jurídica de la Escuela de Derecho y Ciencias Sociales, sumada al reconocimiento y clasificación de cuatro grupos de investigación por parte de Colciencias, que a la postre fue otro de los grandes bastiones y fortalezas para que el Ministerio de Educación Nacional otorgara el registro calificado por siete años al programa de Derecho de nuestra Corporación Universitaria del Meta, llevándolo a ser el mejor de la región con reconocimiento nacional.

No se puede dejar pasar por alto el posicionamiento de los egresados, magistrados, jueces, fiscales, personeros, alcaldes, diputados concejales, docentes universitarios, directivos de importantes entidades públicas y privadas y excelentes litigantes.

Congratulaciones abogados unimetenses por estos 19 años de la nuestra facultad.

Villavicencio, abril 30 de 2013
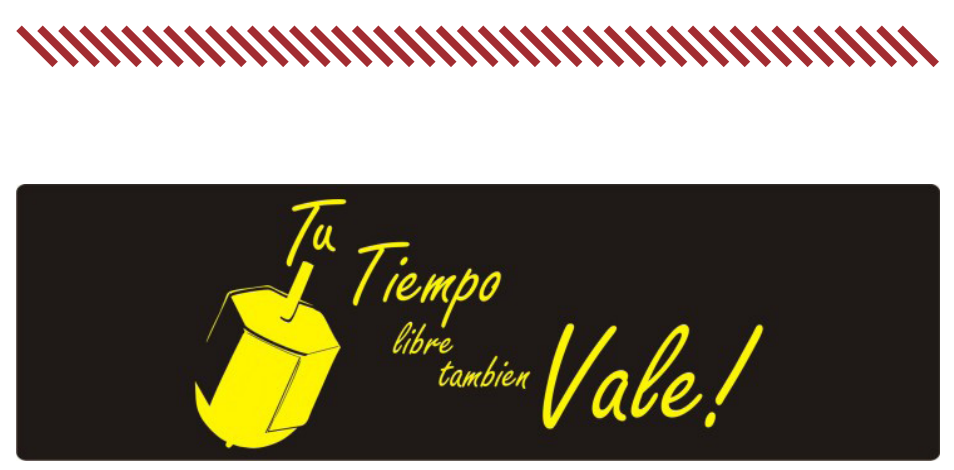

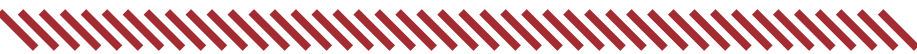

